\title{
LOKABASA
}

Jurnal Kajian Bahasa, Sastra, dan Budaya Daerah serta Pengajarannya

Volume 10, No. 1, April - 2019, Hal. 1-11

p-2338-6193 (print) | e-2528-5904 (online)

Homepage: http://ejournal.upi.edu/index.php/lokabasa doi: 10.17509/jlb.v10i1

\section{Nilai Keagamaan dalam Wawacan Babad Salira}

\author{
Anisa Yunidawati \\ SMP Negeri 6 Sukabumi \\ anisayunidawati@gmail.com
}

\begin{abstract}
Sejarah Artikel: Diterima (28 November 2018); Diperbaiki (24 Desember 2018); Disetujui (01 Maret 2019); Pusblished (30 April 2019)

Bagaimana mengutip artikel ini (dalam gaya APA): Yunidawati, A. (2019). Nilai keagamaan dalam Wawacan Babad Salira. Lokabasa, 10(1), 1-11. doi: 10.17509/jlb.v10i1.16926
\end{abstract}

Abstrak: Penelitian ini dilatarbelakangi oleh kurangnya pengetahuan masyarakat mengenai wawacan, padahal sebagai salah satu karya sastra genre puisi, wawacan mengandung rima dan di dalamnya sarat akan nilai-nilai luhur yang bisa dijadikan contoh dan cerminan. Penelitian ini bertujuan untuk mendéskripsikan dan menganalisis transliterasi naskah, jenis rima, dan nilai keagamaan dalam "Wawacan Babad Salira". Metode yang digunakan adalah metode deskriptif. Sumber data dalam penelitian ini adalah naskah "Wawacan Babad Salira" yang ada di Desa Cilimus, Kecamatan Situraja, Kabupaten Sumedang. Teknik pengumpulan data menggunakan teknik studi pustaka, wawancara, dan dokumentasi. Sedangkan dalam pengolahan data menggunakan teknik analisis secara langsung. Instrumen yang digunakan adalah pedoman wawancara dan kartu data. Dari hasil transliterasi, bisa diketahui bahwa isi "Wawacan Babad Salira" menerangkan tentang nasihat dan wejangan, khususnya yang berhubungan dengan nilai keagamaan. Data yang diperoleh dari "Wawacan Babad Salira" terdapat 315 rima. Dari hasil analisis, ditemukan 10 jenis rima yang terdiri dari purwakanti pangluyu, purwakanti maduswara, purwakanti cakraswara, purwakanti laraspurwa, purwakanti larasmadya, purwakanti laraswekas, purwakanti mindoan kawit, purwakanti mindoan wekas, purwakanti margaluyu, dan purwakanti rangkepan. Secara garis besar, rima yang paling banyak ditemukan adalah jenis purwakanti margaluyu yang berjumlah 109. Nilai keagamaan yang terkandung dalam naskah meliputi dasar-dasar ajaran agama Islam seperti akidah, syari'ah, dan akhlak. Terdapat 18 nilai keagamaan. Nilai keagaamaan yang paling banyak diterangkan adalah tentang akhlak.

Kata Kunci: Wawacan; transliterasi; rima; nilai keagamaan

\section{Religion Values in Wawacan Babad Salira}

Abstract: The background of the research is the lack of public knowledge about wawacan, whereas as one of the literary works of poetry genre, wawacan consists of purwakanti (rhyme) which contained spiritual values that can be used as guidance and reflections. This research aimed to describe and analyze the transliteration of manuscripts, rhymes, and religious values in "Wawacan Babad Salira". The method used was descriptive method. The sources of the data in this research was the manuscript of "Wawacan Babad Salira" in Desa Cilimus, Situradja, Kabupaten Sumedang. In collecting the data, this research employed a technique such as literature study, interview, and documentation. While in processing the data, this research used direct analysis technique. The instruments used were the interview guides and data cards. The result of analysis revealed that the contents of "Wawacan Babad Salira" manuscript explained about the advice and discourses, especially those related to religious values. The data obtained from "Wawacan Babad Salira" were 315 rhymes. The results of the research revealed 10 types of rhyme consisting of purwakanti pangluyu, purwakanti maduswara, purwakanti cakraswara, purwakanti laraspurwa, purwakanti larasmadya, purwakanti laraswwaas, purwakanti mindoan kawit, purwakanti mindo wekas, purwakanti margaluyu, and purwakanti rangkepan. In general, the most common rhyme was purwakanti margaluyu type which consisted of 109. There were 18 religious values contained in the text covered religious basics teachings of Islam such as aqidah, syari'ah, and morals. The religious values that most frequently explained are about morals.

Keywords: Wawacan; transliteration; the rhyme; religious value 


\section{PENDAHULUAN}

Bahasa dan sastra merupakan dua hal yang berbeda tapi saling memengaruhi. Bahasa memiliki kedudukan dalam menuangkan pikiran, pendapat, pandangan, atau ide penutur kepada pemirsa, baik secara lisan maupun tulisan. Hal itu dapat terwujud dalam bentuk karangan, seperti: cerpen, novel, puisi, cerita pantun, dan wawacan, yang di dalamnya memuat gagasan dan ide pengarang yang ingin disampaikan kepada pembaca. Jika cerpen, novel, dan puisi termasuk karya sastra modern, lain halnya dengan cerita pantun dan wawacan yang termasuk ke dalam karya sastra klasik.

Wawacan merupakan salah satu karya sastra klasik dalam bentuk puisi. Wawacan memiliki cerita yang panjang, dibentuk menggunakan patokan pupuh, serta memiliki banyak bagian dalam alur ceritanya. Wawacan mulai dikenal pada abad ke-17. Hal ini berdasarkan pada keterangan bahwa bentuk pupuh yang melatarbelakangi munculnya wawacan berasal dari kesusastraan Jawa yang masuk kira-kira pada abad ke-17 (Koswara, 2013, hlm. 82; Suherman, 2016, hlm 182 \& 2017, hlm. 35). Wawacan merupakan salah satu kesusastraan Sunda, serta tidak lepas dari bahasa sebagai media dalam menyampaikannya. Selain itu, wawacan termasuk karya sastra genre puisi yang sarat akan rima.

Rima merupakan bagian dari gaya bahasa (style) yang menjadi pengikat antara bahasa dan sastra. Style, stail, atau gaya ialah cara yang khas dipergunakan oleh seseorang untuk mengutarakan atau mengungkapkan diri; gaya pribadi (Shipley, dkk. dalam Wibowo, 2017, hlm. 35). Artinya ketika suatu karya sastra mementingkan pemakaian rima, hal ter-sebut bisa menjadi ciri bahwa pengarang memiliki kemampuan dalam memilih diksi yang tepat.

Menurut Salmun (1958, hlm. 28), rima atau purwakanti adalah kalimat yang mengandung kata, suku kata, bunyi, maupun aksara yang sama atau mirip, antara yang awal dan ahir. Sama halnya dengan pendapat Salmun, Iskandariwassid (1996, hlm. 120-121) menjelaskan bahwa rima adalah bunyi kata-kata yang sama dalam sebuah kalimat, klausa, atau frasa, terutama dalam bentuk puisi; letaknya sejajar, horisontal (dalam satu kalimat), atau vertikal (antarjajaran, antarkalimat). Berdasarkan ciri khas kebahasaannya, Salmun (1958, hlm. 29-38) membedakan rima atau purwakanti menjadi 9 jenis, yaitu: purwakanti pangluyu, purwakanti maduswara, purwakanti cakraswara, purwakanti laraspurwa, purwakanti larasmadya, purwakanti laraswekas, purwakanti mindoan kawit, purwakanti mindoan wekas, dan purwakanti margaluyu.

Di daerah Sumedang, tepatnya di Kecamatan Situraja, terdapat naskahnaskah wawacan yang secara turuntemurun diwariskan. Salah satunya adalah naskah "Wawacan Babad Salira". Naskah yang di dalamnya meliputi teks, merupakan objek kajian filologi. Menurut Baried (1985, hlm. 87), filologi dalam arti yang lebih luas adalah ilmu yang meneliti mengenai perkembangan kerohanian suatu bangsa dan khusus untuk menyelidiki kebudayaan berdasarkan bahasa dan kesusastraannya. Umumnya naskah-naskah kuno seperti wawacan ditulis menggunakan aksara Arab-Pegon dan Cacarakan. Oleh sebab itu, agar isi yang diceritakan dalam wawacan bisa tersampaikan kepada pembaca, perlu adanya kegiatan transliterasi.

Transliterasi ialah penggantian jenis tulisan, huruf demi huruf dari abjad yang satu ke abjad yang Iain (Baried, 1985, hlm. 65). Misalnya mengganti aksara Pegon menjadi aksara Latin tanpa merubah arti dan isi yang aslinya. Menurut Robson (1994, hlm. 12), tugas utama seorang filolog adalah menjembatani komunikasi yang menghubungkan antara pengarang zaman dulu dengan pembaca zaman sekarang. Salah satu caranya yaitu berusaha agar teks dapat dibaca dan dimengerti. Faturahman (2016, hlm. 19) menegaskan bahwa permasalahan tersebut bisa disele- 
saikan dengan dua cara, yaitu menampilakn (to present) dan menafsirkan (to interpret). To present berarti menampil-kan teks yang asalnya sulit dibaca menjadi teks yang mudah dibaca atau dari teks yang sulit diakses menjadi teks yang mudah diakses oleh masyarakat umum. Tidak cukup hanya dengan menampilkan saja, sebab bisa jadi tidak dimengerti oleh pembaca. Oleh karena itu, diperlukan tahap to interpret agar bisa memberikan pendapat yang sesuai dengan konteks yang ada dalam teks tersebut.

Selain dijadikan barang pusaka, isi sebuah wawacan mengandung nilai dan norma kehidupan. Berdasarkan pada isinya, Ekadjati membagi wawacan ke dalam beberapa kelompok (Ruhaliah, 2011, kc. 96-98), yaitu: ajaran agama; kemasyarakatan; mitologi; pendidikan; pengetahuan; sastra; dan sejarah (babad). Dari jumlah tersebut, wawacan yang menerangkan tentang ajaran agama termasuk yang terbanyak.

Nilai berarti harga (LBSS, 1985, hlm. 7); (Satjadibrata, 2005, hlm 38), sedangkan agama adalah aturan atau undang-undang yang terdapat dalam kitab suci; ajaran mengenai ilmu agar memercayai adanya Allah Swt, serta disampaikan oleh para nabi (Danadibrata, 2015, hlm. 7). Jadi, nilai keagamaan ialah hal-hal yang berhubungan dengan kepercayaan tentang adanya Allah Swt. serta setiap aturannya termuat dalam kitab suci dan disampaikan melalui para nabi. Agama menjadi satu sistem yang mengatur setiap orang yang memegang kepercayaan tersebut, agar melaksanakan segala hal yang dianggap baik dan menjauhi segala larangan-Nya.

Agama Islam merupakan salah satu agama yang memiliki dasar-dasar agama dan sumber hukum. Isi ajaran agama Islam secara garis besar meliputi akidah, syari'ah, dan akhlak (Anshari, 2004, hlm. 45). Akidah adalah salah satu disiplin dalam agama yang berhubungan dengan keyakinan (Ginanjar, 2017, hlm. 104). Hidayat (2015, hlm. 184) menjelaskan bahwa syari'ah adalah seperangkat sistem peraturan yang ditetapkan Allah sebagai pegangan bagi manusia, baik dalam hubungannya dengan Allah (habl min Allâh) maupun dalam hubungannya dengan sesama manusia (habl min al-nâs). Sedangkan akhlak diartikan sebagai sikap yang membentuk perilaku, baik maupun buruk (Ali dalam Ginanjar, 2017, hlm. 109). Biasanya sikap yang baik disebut ahklak mahmudah, sedangkan yang buruk disebut akhlak mazmumah.

\section{METODE}

Penelitian ini termasuk ke dalam penelitian kualitatif dengan menggunakan pendekatan deskriptif. Tujuan penelitian deskriptif adalah mendeskripsikan atau menggambarkan fenomena-fenomena yang ada, baik yang bersifat alami maupun rekaan (Sukmadinata, 2015, hlm. 72).

Sumber data dalam penelitian ini adalah naskah "Wawacan Babad Salira" yang ada di Desa Cilimus, Kecamatan Situraja, Kabupaten Sumedang. Naskah ini ditulis dalam bahasa Sunda dengan menggunakan aksara Pegon, dan memiliki tebal 81 halaman. Jenis kertas yang digunakan adalah kertas leces. Naskah "Wawacan Babad Salira" merupakan naskah koleksi pribadi Uwa Pardi yang diwariskan secara turun-temurun.

Data dalam penelitian ini dikumpulkan dengan beberapa cara, yaitu teknik studi pustaka, wawancara, dan dokumentasi. Studi pustaka ialah cara untuk mengumpulkan bahan penelitian yang berupa buku atau jurnal yang relevan dengan fokus kajian (Satori \& Komariah, 2009, hlm. 152). Wawancara (interview) merupakan salah satu teknik pengumpulan data yang sering digunakan dalam penelitian deskriptif kualitatif atau deskriptif kuantitatif (Sukmadinata, 2015, hlm. 216). Wawancara dilaksanakan baik secara langsung maupun tidak langsung dengan informan yang menjadi sumber data. Sedangkan dokumentasi ialah pengumpulan dokumen dan data-data yang diperlukan 
dalam masalah penelitian, kemudian ditelaah secara intens agar dapat membantu penelitian (Satori \& Komariah, 2009, kc. 149). Teknik wawancara diperlukan untuk mengetahui identitas naskah dari pemilik naskah. Teknik studi pustaka digunakan dalam mencari sumber-sumber teori untuk kebutuhan referensi (teori filologi, rima, wawacan, dan nilai keagamaan). Sedangkan teori dokumentasi digunakan untuk mengetahui jenis rima dan nilai keagamaan yang terkandung dalam naskah "Wawacan Babad Salira". Teknik analisis data dalam penelitian ini menggunakan teknik analisis secara langsung.

Instrumen penelitian berfungsi untuk membantu penelitian agar mendapatkan informasi yang dibutuhkan. Menurut Arikunto (2013, hlm. 203), instrumen penelitian ialah alat atau fasilitas yang dipakai peneliti dalam pengumpulan data agar penelitian lebih mudah dan bisa mendapatkan hasil yang baik, dalam arti lengkap dan sistematis sehingga mudah untuk diolah. Instrumen yang dipakai dalam penelitian ini adalah pedoman wawancara untuk mengetahui identitas naskah "Wawacan Babad Salira". Selain itu, kartu data juga dipakai untuk mengklasifikasikan rima yang ada dalam naskah berdasarkan jenisnya.

Prosedur dalam penelitian ini adalah: (1) Persiapan, peneliti menentukan objek penelitian dan rumusan masalah; (2) Melaksanakan Penelitian dan Pengumpulan Data, peneliti melaksanakan transliterasi naskah, membuat instrumen untuk membantu penelitian, dan menentukan bagian wawacan yang mengandung rima atau nilai keagamaan; (3) Analisis Data, peneliti mendeskripsikan naskah, menyusun transliterasi naskah, membuat klasifikasi rima, dan menentukan nilai keagamaan yang terkandung dalam naskah; dan (4) Kesimpulan, peneliti menyimpul-kan hasil penelitian setelah melaksanakan analisis data.

\section{HASIL DAN PEMBAHASAN}

Berdasarkan pada hasil penelitian mengenai naskah "Wawacan Babad Salira", ditemukan hasil transliterasi, jenis rima, dan nilai keagamaan.

\section{Transliterasi}

Naskah "Wawacan Babad Salira" merupakan koleksi pribadi Uwa Pardi yang diwariskan secara turun-temurun, letaknya di Desa Cilimus, Kecamatan Situraja, Kabupaten Sumedang. Dalam naskah ditulis bahwa penyalin naskah bernama Mudasir yang beralamat di Desa Babakan Bandung, Kecamatan Situraja, Kabupaten Sumedang. Naskah ini ditulis dalam kertas leces dengan menggunakan aksara Pegon dan bahasa Sunda. Tebal naskahnya ialah 81 halaman. Menurut pemilik naskah, dulu "Wawacan Babad Salira" sering ditampilkan pada perayaan pernikahan.

Pupuh yang digunakan dalam "Wawacan Babda Salira" adalah dangdanggula, asmarandana, sinom, dan kinanti. Jumlah bait dalam wawacan ini ialah 261 bait. Pupuh yang sering digunakan adalah pupuh kinanti.

Isi "Wawacan Babad Salira" berupa nasihat dan wejangan, khususnya yang berhubungan dengan nilai keagamaan. Dalam naskah ini, diterangkan bagaimana cara yang benar untuk manusia hidup di dunia, dengan tetap mengedapankan alam akhirat yang sejatinya akan dirasakan. Inti dari "Wawacan Babad Salira" adalah setiap manusia berasal dari Allah dan akan kembali kepada-Nya. Harus selalu melibatkan Allah dalam segala urusan agar mendapatkan kemaslahatan.

\section{Rima atau Purwakanti}

Rima atau purwakanti adalah istilah sastra yang dipakai untuk menyebutkan salah satu cara dalam membuat sebuah ikatan kalimat. Purwakanti yang pertama kali dikenal dalam bahasa Sunda hanya ada dua, yaitu purwakanti yang memiliki kesamaan dalam konsonan dan purwakanti yang memiliki kesamaan dalam vokal 
(Salmun, 1958, hlm. 28). Kemudian muncul purwakanti baru dari hasil perbandingan dan persamanaan antara purwakanti Sunda dengan yang lain. Dari dua bentuk tadi, purwakanti diklasifikasikan oleh Salmun menjadi 9 jenis, yaitu: purwakanti pangluyu; purwakanti maduswara; purwakanti cakra-swara; purwkanti laraspurwa; purwakanti larasmadya; purwakanti laraswekas; purwakanti mindoan kawit; purwakanti mindoan wekas; dan purwakanti magaluyu. Selain itu, istilah purwakanti rangkepan digunakan oleh peneliti dalam menyebut-kan purwakanti yang memiliki lebih dari satu ciri purwakanti dalam adegan kalimat yang sama. Dari hasil pengumpulan data, ditemukan 315 purwakanti.

\section{Purwakanti Pangluyu}

Dari hasil analisis data, ditemukan 15 purwakanti pangluyu. Purwakanti ini mengacu pada purwakanti yang ada dalam satu kalimat, patokannya adalah bunyi (suku kata) yang sama dalam kata-kata di dalam kalimat tersebut. Contohnya:

titi surti ati-ati

(tindak-tanduk harus berhati-hati)

Berdasarkan contoh di atas, terlihat bahwa suku kata yang menjadi ciri purwakanti pangluyu ada dalam satu kalimat, yaitu pada suku kata /ti/ dalam kata titi, surti, dan ati-ati.

\section{Purwakanti Maduswara}

Berdasarkan pada analisis data, terdapat 42 purwakanti maduswara. Purwakanti maduswara ialah rima yang dibentuk oleh bunyi vokal. Contohnya:

babad rasa pangrasa sorangan

(babad rasa perasaan sendiri)

Sesuai dengan ciri purwakanti maduswara, pada contoh di atas bunyi vokal yang menjadi pemanisnya adalah vokal $/ a /$.

\section{Purwakanti Cakraswara}

Purwakanti cakrswara dalam "Wawacan Babad Salira" ada 9. Rima ini mengacu pada bunyi vokal yang tertukar dalam dua kata yang berdekatan. Contohnya:

kadéngéna ciga lain

(terdengar bukan seperti sebenarnya)

Berdasarkan contoh di atas, bunyi vokal /i/ dan /a/ pada kata ciga tertukar tempatnya menjadi bunyi vokal /a/ dan /i/ pada kata lain. Hal tersebut sesuai dengan ciri purwakanti cakraswara.

\section{Purwakanti Laraspurwa}

Jenis purwakanti laraspurwa yang ditemukan dari hasil analisis data ada 11. Rima ini mengacu pada suku kata yang sama serta letaknya berada di depan, ketika memulai sebuah kata. Bisa dalam satu kalimat maupun antarkalimat. Contohnya:

nganteur ngidul nganteur ngalér

(mengantar ke selatan dan utara)

Berdasarkan contoh di atas, suku kata lng/ menjadi ciri purwakanti laraspurwa karena diulangi di depan kata nganteur, ngidul, dan ngaler.

\section{Purwakanti Larasmadya}

Dari hasil analisis data, ditemukan 16 purwakanti larasmadya. Rima ini mengacu pada purwakanti yang berada di tengahtengah kalimat. Contohnya:

\section{Kasangka kaburu sirna dituding kaburu lain (disangka tapi hilang dituduh tapi salah)}

Berdasarkan contoh di atas, terlihat bahwa kata /kaburul yang diulangi di tengah setiap kalimat menjadi ciri kalimat di atas termasuk purwakanti larasmadya.

\section{Purwakanti Laraswekas}

Terdapat 48 purwakanti laraswekas yang ditemukan dari hasil analisis data. 
Rima ini mengacu pada bentuk konsonan atau suku kata yang sama serta letaknya berada di ahir, baik dalam datu kalimat maupun antarkalimat.

\section{Bageur ogé kitu mah teu hasil hanteu surup kana basa misal jadi nyawana paséngsol (baikpun tak akan membawa hasil tak sama dengan bahasa misal nyawa menjadi tidak seperti seharusnya)}

Berdasarkan contoh di atas, bisa disimpulkan bahwa bunyi konsonan yang diulangi dalam setiap kalimat ialah konsonan /l/. Oleh sebab itu, kalimat di atas termasuk ke dalam purwakanti laraswekas.

\section{Purwakanti Mindoan Kawit}

Jenis purwakanti mindoan kawit yang ditemukan dari hasil analisis data ada 37. Rima ini mengacu pada ciri rima yang muncul akibat dari adanya kata yang diulangi dalam setiap awal kalimat. Contohnya:

\section{seubeuh ngaji seubeuh bakti seubeuh dagang seubeuh tani seubeuh suhud seubeuh sujud seubeuh nepi ka usaha (cukup mengaji cukup berbakti cukup berdagang cukup bertani cukup suhud cukup sujud cukup sampai berusaha)}

Berdasarkan contoh di atas, kata yang diulangi di awal setiap kalimat yang menjadi ciri purwakanti mindoan kawit ialah kata /seubeuh/.

\section{Purwakanti Mindoan Wekas}

Dari hasil analisis, hanya ditemukan 2 purwakanti mindoan wekas. Rima ini mengacu pada kata yang dilangi dan letaknya berada di akhir setiap kalimat. Contohnya:

nyéta kana urut tadi méméh éling kuring tadi

(yaitu kembali pada yang tadi Tadi sebelum saya sadar)
Berdasarkan contoh di atas, terlihat bahwa kata yang berima berada di akhir setiap kalimat. Sehingga kalimat di atas termasuk ke dalam purwakanti mindoan wekas sebab kata /tadi/ diulangi disetiap akhir kalimat.

\section{Purwakanti Margaluyu}

Berdasarkan hasil analisis data, terdapat 109 purwakanti margaluyu. Rima ini mengacu pada kata yang berada di akhir kalimat kemudian diulangi lagi di awal kalimat setelahnya. Contohnya:

\section{Sangkaan kuring kiwari \\ kiwari pédah geus tepang \\ tepang reujeung nu baréto \\ baréto kuring teu aya \\ (prasangka saya sekarang \\ sekarang telah bertemu \\ bertemu dengan yang terdahulu \\ dulu saya tidak ada)}

Berdasarkan contoh di atas, kata yang berada di akhir diulangi lagi di awal kalimat setelahnya. kata /kiwari/ di akhir kalimat pertama diulangi di awal kalimat kedua, kata /tepang/ di akhir kalimat kedua diulangi di awal kalimat ketiga, begitu seterusnya. Ciri tersebut termasuk ke dalam purwakanti margaluyu.

\section{Purwakanti Rangkepan}

Purwakanti rangkepan yang ditemukan dari hasil analisis data ada 25 . Rima ini dipakai untuk menyebutkan jenis rima yang memiliki ciri purwakanti lebih dari satu dalam kalimat yang sama.

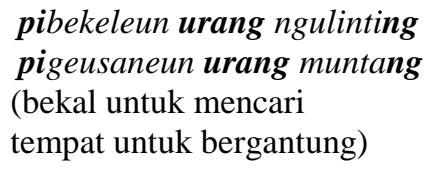

Berdasarkan contoh di atas, purwakanti rangkepan dipakai untuk menyebutkan purwakanti laraspurwa yang dibentuk oleh suku kata /pil, purwakanti larasmadya yang dibentuk oleh kata lurang/, dan purwakanti laraswekas yang dibentuk oleh konsonan /ng/. 


\section{Nilai Keagamaan}

"Wawacan Babad Salira merupakan salah satu wawacan yang berisi tentang keagamaan. Nilai keagamaan yang diterangkan mengacu pada dasar ajaran Islam, meliputi akidah, syari'ah, dan ahlak. Setelah menemukan nilai-nilai yang terkandung dalam naskah, kemudian dicocokkan dengan sumber hukum Islam.

Sumber hukum Islam yang utama adalah Al-Qur'an dan hadist, sedangkan ijtihad merupakan ketetapan untuk menentukan hukum yang di anggap kurang jelas dalam Al-Qur'an dan hadits. Menurut Nur (dalam Daulay, 2014, hlm. 33), AlQur'an secara istilah berarti kalam Allah yang diturunkan kepada Nabi Muhammad saw. melalui perantara malaikat jibril yang ditulis dalam mashahif, diriwayatkan kepada umatnya secara mutawatir, dianggap sebagai ibadah ketika membacanya, diawali dengan surat alFatihah dan diakhiri dengan surat an-Naas. Menurut Hidayat, (2015, hlm. 61-62), hadits adalah berita yang datang dari Rasulullah saw. mengenai ucapannya $(q a w l)$, perbuatannya $\left(f i^{\prime} l\right)$ atau perbuatan dan ucapan sahabat yang berhubungan dengan perkara agama yang disetujui atau dibenarkan oleh Rasulullah saw. (taqrir). Sedangkan ijtihad adalah bersungguhsungguh menggunakan akal pikiran untuk merumuskan dan menetapkan (penilaian) hukum atas sesuatu perkara yang tidak ditemukan kepastian hukumnya dalam AlQur'an maupun sunnah (Hidayat, 2015, hlm. 72).

Di bawah ini dijelaskan mengenai beberapa nilai keagamaan yang terkandung dalam "Wawacan Babad Salira".

\footnotetext{
Akidah

Dalam "Wawacan Babad Salira", ditemukan bagian-bagian yang berhubungan dengan akidah, seperti: (1) sifat-sifat Allah; (2) asma'ul husna; (3) alam akhirat sebagai suatu hal yang nyata; dan (4) malaikat selaku utusan Allah.
}

Sifat-sifat Allah yang disebutkan dalam naskah "Wawacan Babad Salira" adalah wujud, qidam, baqo, mukhalafatu lilhawaditsi, qiyamuhu binafsihi, wahdaniyyat, qudrat, iradat, 'ilmu, hayyat, sama', bashor, kalam, qodiron, muridan, 'aliman, hayyan, sami'an, bashiron, dan mutakaliman. Bagian dalam naskah yang menjelskan sifat-sifat Allah seperti di bawah ini.

Sami'an anu ngadangu, ngulik lian tina ati, ati nu mahi sorangan, ngandelkeun katigin ati, tiap ngadéngé nu enya, nya sorangan anu harti. (sami'an yang mendengar,

Bashiron anu geus puguh, puguh awas nu ningali, ningali kamana-mana, kamana-mana geus mani, mana anu geus uninga, sorangan anu ningali.

Mutakaliman nu nyaur, nyaur nyaritakeun diri, diriksana ku sorangan, nganteur nyarita pirbadi, dibabar kalimah sahadat, sada omong kamadasyir.

Dari penggalan naskah di atas, terlihat ada beberapa sifat Allah yang disebutkan, yaitu sami'an, bashiron, dan mutakaliman. Hal tersebut menekankan bahwa dalam naskah terdapat nilai keagamaan yang berhubungan dengan sifat-sifat Allah.

Bahasan kedua dalam akidah yaitu mengenai asma'ul husna. Adapun asma'ul husna yang disebutkan dalam naskah yaitu Ar-Rohman dan Al-Khaliq. Penggalan dalam naskah yang menjelaskan tentang asma'ul husna adalah sebagai berikut.

Buktina rohman téh murah, murahna nu Maha Suci, lain ngolo kawas jalma, bayar sakali teu mahi, ari murahna Yang Widi, 
sakali saumur hirup,

rohman ngan hiji-hijina,

dipastikeun kana mati,

mani hirup jagjagna jadi kaula.

Asma'ul husna yang disebutkan dalam penggalan naskah di atas adalah $A r$ Rohman, yang artinya Maha Pengasih. Dari penggalan naskah di atas, terlihat bahwa naskah "Wawacan Babad Salira" mengandung nilai keagamaan yang berhubungan dengan akidah, khususnya mengenai asma'ul husna.

Bahasan ketiga ialah tentang keyakinan terhadap adanya alam akhirat. Dalam naskah disebutkan seperti di bawah ini.

ahérat da enggeus nyata.

Ahérat mah anu geus kaharti, ahérat mah dina jero manah, ahérat anu teu capé,

ahérat mah taya napsu,

ahérat mah suci ati,

ahérat mah pasrah manah,

ahérat satuhu,

ahérat téh anu tunggal,

ahérat téh ieu buktina sim kuring,

ahérat lega lugina.

Penggalan di atas menjadi bukti bahwa dalam naskah terdapat bagian akidah yang membahas tentang alam akhirat.

Bahasan terakhir mengenai akidah adalah penjelasan mengenai malaikat selaku utusan Allah. Malaikat yang disebutkan dalam "Wawacan Babad Salira" ialah Jibril, Mikail, Isrofil, dan Izroil. Penggalan dalam naskah yang memuat tentang pembahasan malaikat adalah sebagai berikut.

Hiji medal ti Yang Agung,

malaikat anu ngaping,

jabaroil minkail téa,

isrofil 'ijjroil deui,

opatanana utusan,

utusan nu Maha Suci.
Dari penggalan di atas, terlihat bahwa malaikat yang merupakan rukun iman kedua termasuk dalam pembahasan akidah dalam naskah "Wawacan Babad Salira".

Nilai-nilai keagamaan di atas sinkron jika dihubungkan dengan sumber hukum yang utama, yaitu Al-Qur'an. Contohnya mengenai alam akhirat yang disebutkan dalam naskah dijelaskan juga dalam AlQur'an, yaitu dalam surat Al-'Ankabut: 64 (Shaleh, 2003, hlm. 462).

"Jeung taya lian ieu kahirupan dunya téh ngan kaheureuyan jeung kaulinan. Jeung saéstuna nagri ahérat téh kahirupan anu sabenerna, upama maranéhna nyarahoeun mah.” (Q.S. Al-“Ankabut: 64)

Isi yang dijelaskan dalam naskah sesuai dengan keterangan dalam AlQur'an. Dalam naskah disebutkan bahwa akhirat merupakan suatu hal yang nyata, sedangkan dalam Al-Qur'an diterangkan bahwa akhirat merupakan kehidupan yang sebenarnya. Keduanya sama-sama menegaskan tentang alam akhirat yang sudah pasti akan dirasakan oleh setiap manusia.

\section{Syari'ah}

Nilai keagamaan dalam naskah "Wawacan Babad Salira" yang menerangkan tentang syariah ialah shalat dan ibadah haji.

Bahasan mengenai shalat dalam naskah meliputi rukun, manfaat, dan waktu shalat fardhu. Rukun shalat yang disebutkan di antaranya adalah berdiri, sujud, ruku, dan salam. Penggalan naskahnya seperti di bawah ini.

Da asal éta ti dinya,

nya hayang ka dinya deui,

deui ngaboga asalna,

asalna opat perkawis,

seuneu angin cai bumi,

ngadeg ruku sujud lungguh,

ngadeg téh asalna panas,

panas anu dina ati, 
Dari penggalan naskah di atas, rukun shalat yang disebutkan adalah berdiri, ruku, dan sujud. Tiga hal tersebut merupakan bagian dari rukun shalat yang dijelaskan dalam naskah "Wawacan Babad Salira".

Hal-hal yang berkenaan dengan ibadah haji yang dijelaskan dalam naskah ialah rukun dan manfaat melaksanakan ibadah haji. Rukun haji tersebut adalah wukuf. Penggalan dalam naskahnya seperti di bawah ini.

\section{Ari cahya caang terang,}

terangna pangrasa ati,

ati geus teu mangmang béja,

kajadianana éling,

éling ka nu geus kaharti,

harita téh tuluy wukuf,

nya wukuf di gunung Arfah,

ngeureunkeun panasna ati,

ati kuring geus teu panas ku nu lian.

Dari penggalan di atas, bisa dilihat bahwa rukun haji merupakan bagian naskah yang berhubungan dengan urusan syri'ah.

Pembahasan mengenai syari'ah dalam naskah sesuai dengan sumber hukum Islam. Salah satunya yaitu tentang rukun yang merupakan bagian dari rukun shalat, juga dibahas dalam hadits (Al-Abani, 2009, hlm. 64)

“... Shalatlah dengan berdiri, jika tidak mampu shalatlah dengan duduk, jika tidak mampu shalatlah dengan berbaring." (H.R. Bukhari)

Baik dalam naskah maupun hadits, sama-sama menyebutkan tentang ruku yang merupakan salah satu rukun shalat.

\section{Akhlak \\ Bahasan nilai keagamaan mengenai akhlak dalam naskah "Wawacan Babad Salira" dibagi menjadi dua kategori, yaitu akhlak mahmudah (baik) dan akhlak mazmumah (buruk).}

Akhlak mahmudah yang terdapat dalam naskah, adalah: (1) anjuran bersabar dan bertawakal; (2) pahala melakukan kebaikan; (3) anjuran bertaubat; dan (4) keutamaan berbakti kepada ibu dan bapak. Salah satu penggalan dalam naskah mengenai akhlak mahmudah di antaranya seperti di bawah ini.

\section{Manahaneun ti kiwari, wara-wiri jeung agama, agama nu ngalalakon, lakonaneun saréréa, réa pisan kasalahan, salah mah teu kudu jauh, tobat baé ka sorangan.}

Penggalan naskah di atas berhubungan dengan anjuran bertaubat yang diterangkan dalam Al-Qur'an, yaitu dalam surat Al-Imran: 135 (Shaleh, 2003, hlm. 533).

"Jeung jalma-jalma anu dina mangsa ngalampahkeun kajahatan atawa anu nganiaya dirina buru-buru maranéhna inget ka Alloh, sarta terus ménta dihampura tina dosa-dosana; jeung naha lain taya deui nu ngahampura dosa salian ti Alloh? Jeung maranéhna henteu tonggoy dina kagoréngan anu dilampahkeunana bari jeung maranéhna nyaraho.” (Q.S. Al-Imran: 135)

Dalam naskah dan dalil di atas, keduanya menerangkan tentan anjuran melakukan taubat untuk semua manusia yang telah melakukan perbuatan dosa.

Sedangkan akhlak mazmumah yang dijelaskan dalam naskah ialah: (1) larangan berbuat pamrih; (2) larangan berbuat dengki; (3) larangan berbuat riya; (4) larangan berbuat suudzon; (5) larangan berbuat sombong; (6) larangan berbuat dzolim; (7) larangan berbuat syirik; dan (8) larangan hubud dunia. Penggalan dalam naskah yang menjelaskan salah satu akhlah mzmumah di antaranya sebagai berikut.

Sentar ati tara bening,

tangtu sakawenang-wenang,

nyarita gé seuri konéng,

taya tanda Ujang lanang,

sarta ulah hayang meunang, 
sanajan jeung urang gunung,

da sarua pada wenang.

Dari penggalan naskah di atas, bisa disimpulkan bahwa dzolim atau aniaya merupakan perbuatan yang dilarang. Begitupun dalam Al-Qur'an, yaitu dalam surat Asy-Syura: 42 (Shaleh, 2003, hlm. $558)$.

"Saéstuna taya lian tumiba siksaan téh ka jalmajalma nu nganiaya manusa jeung nu nimbulkeun karuksakan di ieu bumi kalawan henteu hak. Nya pikeun maranéhna siksaan anu kacida peurihna." (Q.S. Asy-Syura: 42)

Dari penggalan naskah dan dalil di atas, keduanya menegaskan kepada manusia agar menjauhi perilaku buruk seperti dzolim atau aniaya.

\section{SIMPULAN}

"Wawacan Babad Salira" merupakan salah satu naskah Sunda yang berisi tentang nasihat dan wejangan, khususnya yang berhubungan dengan ajaran agama Islam. Naskah ini memiliki tebal 81 halaman, ditulis menggunakan aksara Pegon dalam bahasa Sunda. Pupuh yang digunakan dalam "Wawacan Babad Salira" ialah dangdanggula, asmarandana, sinom, dan kinanti. Jumlah bait dalam wawacan ini adalah 261 bait.

Dalam "Wawacan Babad Salira" terdapat 315 rima atau purwakanti. Jenis rima yang ditemukan ada 10, yaitu purwakanti pangluyu, purwakanti maduswara, purwakanti cakraswara, purwakanti laraspurwa, purwakanti larasmadya, purwakanti laraswekas, purwakanti mindoan kawit, purwakanti mindoan wekas, purwakanti margaluyu, dan purwakanti rangkepan. Purwakanti rangkepan dipakai untuk menyebutkan jenis rima yang memiliki ciri purwakanti lebih dari satu dalam adegan kalimat yang sama.

Nilai keagamaan yang terkandung dalam "Wawacan Babad Salira" adalah dasar-dasar agama Islam, meliputi akidah, syari'ah, dan akhlak. Nilai keagamaan yang ditemukan dan mengandung unsur akidah, di antaranya adalah: (1) sifat-sifat Allah; (2) asma'ul husna; (3) alam akhirat merupakan satu hal yang nyata; dan (4) malaikat sebagai utusan Allah. Nilai keagamaan yang berhubungan dengan syari'ah adalah shalat dan ibadah haji. Sedangkan pembahasan mengenai akhlak yang terkandung dalam naskah dibagi menjadi dua kategori, yaitu akhlak mahmudah (baik) dan akhlak mazmumah (buruk). Akhlah mahmudah yang terkandung dalam naskah adalah: (1) anjuran bersabar dan bertawakal; (2) pahala melakukan kebaikan; (3) anjuran bertaubat; dan (4) keutamaan berbakti kepada ibu dan bapak. Sedangkan akhlak mazmumah yang dibahas adalah: 1) larangan berbuat pamrih; (2) larangan berbuat dengki; (3) larangan berbuat riya; (4) larangan berbuat suudzon; (5) larangan berbuat sombong; (6) larangan berbuat dzolim; (7) larangan berbuat syirik; dan (8) larangan hubud dunia.

\section{UCAPAN TERIMA KASIH}

Penulis mengucapkan terima kasih kepada semua pihak yang telah mendukung hingga tulisan ini bisa diselesaikan, untuk Haris Santosa Nugraga, M.Pd. dan Temmy Widyastuti, M.Pd. selaku dosen penelaah jurnal. Semoga tulisan ini bermanfaat untuk semua pembaca.

\section{CATATAN PENULIS}

Penulis menyatakan bahwa tidak ada konflik kepentingan terkait publikasi artikel ini. Penulis mengkonfirmasi bahwa data dan artikel ini bebas plagiarisme.

\section{PUSTAKA RUJUKAN}

Al-Albani, M.N. (2009). Sifat Shalat Nabi saw.: Panduan Shalat Rasulullah. Jakarta: Gema Insani.

Anshari, E.S. (2004). Wawasan Islam: Pokok-pokok Pikiran tentang Paradigma dan Sistem Islam. Jakarta: Gema Insani. 
Arikunto, S. (2013). Prosedur Penelitian: Suatu Pendekatan Praktik. Jakarta: Rineka Cipta.

Baried, S.B. (1985). Pengantar Teori Filologi. Jakarta: Pusat Pembinaan dan Pengembangan Bahasa Departemen Pendidikan dan Kebudayaan.

Danadibrata. (2015). Kamus Basa Sunda. Bandung: Kiblat Buku Utama.

Daulay, M.R. (2014). "Studi Pendekatan Alquran". Jurnal Thariqah Ilmiah, 01 ( 01), hlm. 33-34.

Fathurahman, O. (2016). Filologi Indonesia: Teori dan Metode. Jakarta: Prenadamedia Group.

Ginanjar, M.H. (2017). "Pembelajaran Akidah Akhlak dan Korelasinya dengan Peningkatan Akhlak Alkarimah Pesera Didik". Jurnal Pendidikan Islam, 06 (12), hlm. 104 \& 109.

Hidayat, R.T. (2015). Khazanah Istilah AlQuran. Bandung: Kiblat Buku Utama.

Iskandarwassid. (1996). Kamus Istilah Sastra Pangdeudeul Pangajaran Sastra Sunda. Bandung: Geger Sunten.

Koswara, D. (2013). Racikan Sastra: Pangdeudeul Bahan Perkuliahan Sastra Sunda. Bandung: JPBD FPBS UPI.

LBSS. (1985). Kamus Umum Basa Sunda. Bandung: Tarate Bandung.

NN. Wawacan Babad Salira.

Robson, S.O. (1994). Prinsip-prinsip Filologi Indonesia. Jakarta: Pusat Pembinaan dan Pengembangan
Bahasa \& Universitas Leiden. Ditarjamahkeun ku Kentjanawati Gunawan, tina aslina, principles of Indonesian Philology, Leiden: Foris Publication.

Ruhaliah. (2011). Wawacan: Sebuah Genre Sastra Sunda. Bandung: teu diterbitkeun.

Salmun, M.A. (1958). Kandaga Kasusastraan. Bandung-Jakarta: Ganaco.

Satjadibrata, R. (2005). Kamus Basa Sunda. Bandung: Kiblat Buku Utama.

Satori, D. \& Komariah, A. (2009). Metodologi Penelitian Kualitatif. Bandung: Alfabeta.

Shaleh, Q., spk. (2003). Al-Qur'an Tarjamah Sunda. Bandung: Diponegoro.

Suherman, A. (2016). "Naskah wawacan Pandita sawang sebagai Dokumen Sosial (Interpretasi Verbal, Teknis, Logis, Psikologis, dan Faktual)". Lokabasa, 7 (2), hlm. 178-191.

Suherman, A. (2017). "Wawacan Pandita Sawang sebagai Naskah Keagamaan: Tinjauan Kedudukan dan Fungsi”. Manuskripta, 7 (2), hlm. 34-48.

Sukmadinata, N.S. (2015). Metode Penelitian Pendidikan. Bandung: Remaja Rosdakarya.

Wibowo, P.A.W. (2017). "Kekhasan Purwakanthi dalam Empat Karya Sastra Ki Padmasusastra sebagai Cerminan Pandangan Hidup Masyarakat Jawa (Suatu Tinjauan Stilistika)." [Online]. Tersedia: https://jurnal.uns.ac.id/hsb/article. 